УДК 821.І6г.І

ББК $83.3(2 \mathrm{Poc}=\mathrm{Pyc}) 6$
ШЕКСПИР И БОРЬБА

ЗА ВСТРЕЧНЫЙ ПРОМФИНПЛАН, ИЛИ КАК СДЕЛАНО «ВЫСОКОЕ НАПРЯЖЕНИЕ»

(C) 2017 г. Д.С. Московская

Институт мировой литературы

им. А.М. Горького Российской академии наук, Москва, Россия

Дата поступления статьи: 20 апреля 2017 г. Дата публикации: 25 сентября 2017 г.

DOI: I0.22455/2500-4247-20I7-2-3-220-235

Аннотация: В пьесе «Объявление о смерти» (первоначальное название пьесы «Высокое напряжение») Платонов использовал реальные факты, с которыми он познакомился в 1929-І930 гг. во время пребывания на Ленинградском металлическом заводе. Пьеса должна была ответить на политический заказ РАПП представить «живой и конкретный пример предприятий и живых конкретных людей». Платонов с этой задачей справился. Он показал острый конфликт характеров и мировоззрений. В репликах главных героев можно узнать лексику жестких отзывов, данных Платонову его критиками и Сталиным, в их поведении можно угадать судьбы представителей творческой интеллигенции эпохи реконструкции, Маяковского и Зелинского. Особое место в пьесе занимает тема любви, которая переводит события на новый стилевой и содержательный уровень. В производственной пьесе проступают контуры трагедии с чертами «пограничной ситуации», которая ставит в центр событий человека с его правами, с его свободой выбора как единственную подлинную ценность мира. Платонов не мог не быть в курсе дискуссий о Шекспире, которые развернулись в І93І г. Критики РАПП призывали «догнать и перегнать не какого-нибудь Пильняка, - это не большая честь, да и пролетарская литература уже догнала и перегнала - догнать и перегнать Шекспира...». Платонову удалось сочетать высокую поэтику шекспировской трагедии с ликвидацией прорывов на производстве, и он сделал это вопреки общим насмешкам над рапповскими попытками «шекспиризировать» пьесу об ударниках производства.

Ключевые слова: производственное искусство, Андрей Платонов, Сталин, пьеса, Шекспир, документальность, прообраз, дискуссия, РАПП, критика, экзистенциальная ситуация, драматургический узел, иносказание.

Информация об авторе: Дарья Сергеевна Московская - доктор филологических наук, заместитель директора по научной работе, заведующий отделом рукописей, Институт мировой литературы им. А.М. Горького Российской академии наук, ул. Поварская, д. 25 а, г21069 Москва, Россия.

E-mail: info@imli.ru 


\section{SHAKESPEARE AND THE FIGHT FOR PROMFINPLAN, OR HOW HIGH VOLTAGE IS MADE}

This is an open access article distributed under the Creative Commons Attribution 4.0 International (CC BY 4.0)
(C) 20I7. D.S. Moskovskaya

A.M. Gorky Institute of World Literature

of the Russian Academy of Sciences,

Moscow, Russia

Received: April 20, 2017

Date of publication: September 25, 2017

Abstract: In his play Announcement of Death (the initial title of the play High Voltage), Platonov used documentary facts he observed in I929-I930s while staying at the Leningrad metal factory. The play was intended to fulfil the political order of RAPP to represent "a live example of a specific enterprise and specific individuals." Platonov coped with this task. The play tells the story of heroic struggle of engineers and workers endeavoring to implement the factory's work plan. It shows a sharp conflict of characters and worldviews. In the replicas of the main characters, engineers of the "old school," one can recognize vocabulary and style of the harsh reviews of Platonov's work by literary critics and Stalin. In the characters themselves, one can recognize their alter egos - representatives of the so called creative intelligentsia of the reconstruction era, Mayakovsky and Zelinsky. The motif of love plays a special role in the play in that it introduces a new level of meaning. The "manufacture play" reveals a tragedy that stages the "borderline" situation and places a free-willed person at the center of the represented events as the only true value of the world. The essay argues that Platonov was aware of the discussions around Shakespeare unfolding in I93I. RAPP critics encouraged authors "to catch up with and overtake not only some Pilnyak - this it is not a great honor, the proletarian literature has already caught up with him and overtaken him. The challenge is to catch up with and overtake Shakespeare." Platonov succeeded in combining the high tone of Shakespearean tragedy with the plot of the "manufacture play" despite the general sneer at RAPP's attempts to shakespearize plays about Soviet factory leaders - the so called "udarniki."

Keywords: manufacture art, Andrey Platonov, Stalin, drama, Shakespeare, documentary, prototype, discussion, RAPP, criticism, existential situation, dramaturgical knot, allegory.

Information about the author: Darya S. Moskovskaya, DSc in Philology, Deputy Director of the A.M. Gorky Institute of World Literature, Head of the Manuscript Department, A.M. Gorky Institute of World Literature of the Russian Academy of Sciences, Povarskaya 25 a, I21069 Moscow, Russia.

E-mail: info@imli.ru 
Производственная пьеса «Высокое напряжение» (первоначальное название - «Объявление о смерти», в дальнейшем Платоновым не использовалось) стала ответом Платонова на обрушившуюся на него с мая І93І г., после выхода в свет повести «Впрок (Бедняцкая хроника)», сокрушительную критику ревнителей классовой чистоты искусства. Первое, в феврале 1932 г., обсуждение пьесы [I] имело целью выяснить, произошла ли перестройка мировоззрения этого писателя из пролетариата. Вопрос об эстетических достоинствах пьесы мог быть поднят лишь после апрельского (1932) Постановления Политбюро ЦК ВКП(б) «О перестройке литературно-художественных организаций»: 5 июня 1932 г., на творческом вечере Платонова [4, с. 615-618], впервые прозвучала мысль о недюжинном таланте автора. А. Караваева сравнила пьесу с «Последним решительным» Вс. Вишневского. И сравнение было не в пользу последнего: «Пьеса несравненно выше "Последнего решительного” [4, с. 6І6]. Выступавший на вечере Д. Тальников отметил нестандартность произведения: «...ьеса условного реализма, не бытовая, но и не схематическая <...>. Ее условные образы, вместе с тем реалистические, полны художественной типичности и значимости идеологической. Это пьеса идей, идеологических образов-знаков, социально-обнаженных идей, показанных в экспрессионистическом напряжении» [4, с. 6I8].

С «формально-литературной» стороны в 1932 г. рассмотрел пьесу А.М. Горький и охарактеризовал ее как «своеобразную, интересную и достойную сцены», написанную «очень хорошим языком» [5, с. 314].

Современные литературоведы рассматривают «Высокое напряжение» в рамках «литературы факта», поэтики «производственного» искус- 
ства [6, с. 62-72]. Для этого есть основания: Платонов использовал фактический материал, накопленный в г929-І930 гг. во время пребывания на Ленинградском металлическом заводе (ЛМЗ) и на ленинградской Зиновьевской писчебумажной фабрике. Созданная на его основе пьеса была воистину идеальным ответом на Обращение ВЦСПС и РАПП к советским писателям с призывом о ликвидации прорыва на литературном фронте. Сложность задачи, как видел ее теоретик РАПП В. Ермилов, была в том, чтобы суметь изобразить «живой и конкретный пример предприятий и живых конкретных людей», которых должна знать вся страна, и с этой точки зрения провести проверку «лозунга и живого человека, и борьбы с лакировкой». Он подчеркнул: «...задача не только отдавать готовыми и сложившимися этих людей, но задача показать, какие трудности им приходилось преодолевать, и эту среду, которая им помогала это преодолевать. Задача показать лучших людей нашей страны именно в процессе их борьбы»․

«Объявление о смерти» с поставленными партией и РАПП задачами справилось. Установленный факт работы Платонова с писательской бригадой на ЛМЗ [9, с. 6о-6I, 338-343] придал изучению пьесы документально-биографическое направление. В пьесе действуют, вступая в острый конфликт характеров, мировоззрений, ценностей, идей, шестеро мужчин и одна женщина. Из каких былей пришли они, чтобы зажить новой, литературной жизнью?

О главном герое пьесы Мешкове в набросках к пьесе Платонов пишет: «Мешков - обнаженный социально» [7, с. І83]. И правда, открывающий пьесу монолог Мешкова недвусмысленно обращен к недавним событиям жизни общей (страны) и частной (Андрея Платонова) и обнажает острые социальные проблемы времени: «Нужно скончаться <...>. Я мелочь, прослойка, двусмысленный элемент и прочий пустяк <...> никто ко мне в гости не приходит, и мне пойти некуда» [7, с. 203]. «Чужое» слово в монологе Мешкова после разговора с комсомолкой-ударницей Крашениной: «Неужели я отстал, неужели я дурак?..» [7, с. 213] и его спор с «чужими» голосами, сопровождающий чтение заметки о героической гибели во время производственной аварии инженера Абраментова, окрашивают словесный портрет перепуганного «вредителя» неприкрытой иронией: 
Партком, завком, дирекция, рабочие-ударники... о смерти в огне... верного пролетариату товарища, храбрейшего инженера Сергея Дмитриевича Абраментова, пришедшего из рядов врагов... Из рядов врагов! А я откуда? Я врагом не был. Я все время сочувствовал. Я наоборот даже. Я слишком честный, я умираю от честности, потому что я осознал, что я дурак новой жизни, - я стесняюсь жить [7, с. 233].

В причитаниях Мешкова узнается лексика жестких отзывов, данных Платонову его критиками, в частности, самим Сталиным, начертавшим на полях третьего номера «Красной нови» с публикацией повести «Впрок» «дурак и пошляк новой жизни» [2, с. І 50], или функционерами МАПП: «Вот характерный и показательный пример откровенной вылазки классового врага. Я говорю о рассказе Платонова “Впрок” <...> Кадры колхозные, как он изобразил их! Дурак на дураке, идиот на идиоте <...> нам нужно <...> подойти к идейному расстрелу этой публики»². Пародийно снижает Платонов и собственные недавние, I929-І93і гг., покаянные письма Сталину, Горькому, в редакции центральных газет: «Я несколько сознательней его [Макара] $<. .>$ я не герой своего рассказа» [Іо, с. 272, 273], «я увидел, что товарищи <...> правы, что я заблудился и погибаю» [Іо, с. 285], «нижеподписавшийся отрекается от всей своей прошлой литературно-художественной деятельности» [Іо, с. 29I], «я не классовый враг, <...> я классовым врагом стать не могу <...> рабочий класс - это моя родина» [Іо, с. 304]. Сообщая в письме жене о все возрастающих нападках на него, писатель делится планом спасения: «Перемучившись, обдумав все <...> я решил отказаться, отречься от своего литературного прошлого и начать новую жизнь. Об этом я напишу в газеты “Правда" и “Лит<ературная> газ<ета>” <...>. Другого выхода нет. Другой выход - гибель» [го, с. 295]. Платоновское «двунаправленное» слово в монологах Мешкова свидетельствует: в г93і г. автор «Высокого напряжения» был столь же готов к расправе над собой, как и пребывающий в ожидании «чистки» его герой. В набросках к пьесе эта в глубинном смысле экзистенциальная ситуация лета І93і г., в которой оказались представители творческой и научной интеллигенции, лаконично очерчена обращением Абраментова к портрету Дзержинского: «Ты меня ругал, я тебя уважал, в 
конце пятилетки я попрошусь к стенке» [7, с. І89]. Рядом с небескорыстным, скуповатым и трусливым Мешковым, этим «дураком новой жизни», который, подобно эрдмановскому самоубийце, так и не решится на суицид, высится фигура его антипода, «товарища пролетариата» Абраментова, одинокая, мощная, сумрачная. В его образе и судьбе, емко переданных в диалоге с Девлетовым, собралась вся полнота трагического модуса пьесы: «Скажите - вы белогвардеец? Абраментов. - Был. Девлетов. - А теперь? Абраментов. - Теперь я одинокий» [7, с. 200].

Фигура Абраментова переводит события на новый стилевой и содержательный уровень, и в конъюнктурной партийной суете проступают контуры трагедии с чертами «пограничной ситуации», ставящей в центр событий человека с его судьбой, с его правами, с его свободой выбора как единственную подлинную ценность мира. Наброски к пьесе и восстановленная правка автографа первой редакции «Высокого напряжения» представляют несовместимое с жизнью и единственно отвечающее реальности первой пятилетки понятие свободы этого трагического героя, которое не войдет в текст ни одной из последующих редакций: «Абраментов: там только одна свобода - свобода исчезновения, свобода быть забытым» [7, с. I96]; «Сережа, [y нас есть / одна у нас с тобой / одна свобода] ты скоро уйдешь в материк, в [тесноту земли, и я тоже] тесную землю» [7, с. 23I].

Мне уже приходилось называть события и указывать лица, послужившие реальным источником сюжета и образов «Высокого напряжения». Это инициированная парторгом завода П.И. Семячкиным борьба за встречный план, повлекшая производственные аварии [8, с. I78-237], и противостояние заданным парторгом «темпам» со стороны инженеров «старой школы», среди которых были прежний директор Металлического завода А.Ю. Винблад, заведующий турбинным цехом В.И. Андреев, назначенный главным конструктором паровых турбин в І929 г. М.И. Гринберг, инженер С.А. Бобровщиков, И.И. Кириллов, М.Я. Бень, Ф. Кравченко, Б.В. Шестакович.

Документальный пласт «Высокого напряжения» - низшая ступень политического и философского иносказания, призванного создать обобщающий образ времени. Следующий уровень образуют события последнего года жизни В. Маяковского. Этот «внебрачный сын современности», «сми- 
ренно ожидавший» от РАПП «усыновления»3 [13, с. 27], прообразуя собою Абраментова, стал трагическим героем и жертвой «высокого напряжения» реконструктивного периода. Вспоминается определение Тальникова: «Это пьеса идей, идеологических образов-знаков, социально-обнаженных идей, показанных в экспрессионистическом напряжении». Ни вступление в РАПП, ни Іоо томов его партийных книжек не дали Маяковскому желанного «усыновления», и он ушел в «тесную землю», доказав самоценность несовместимого с установившимся внешним миропорядком личного бытия. Разбор причин смерти Маяковского на страницах центральной прессы поясняет цитированный выше комментарий Мешкова к газетному некрологу: «“...о смерти в огне... верного пролетариату товарища, <...> пришедшего из рядов врагов...” Из рядов врагов! А я откуда?» Абраментов, подобно Маяковскому, анархоиндивидуалист, не более чем «товарищ пролетариата», так и не ставший, несмотря на все усилия, пролетарием.

Характерна для платоновского окружения г929-г932 гг. и фигура инженера Жмякова, «радостного человека средних лет». Управляя пультом турбины, он пританцовывает и напевает: «Их паровоз летит вперед, а нам всем - остановка!..» «Элегантный и грустный до торжественности», он распоряжается у гроба Абраментова, заказывает оркестр, полагая, что «печаль растворится в звуках», а звуки рассеются.

В последнем акте его ожидает жесткий диалог с директором завода Девлетовым, скульптурно одетым в риторику героя-резонера классицистической пьесы:

Девлетов. - Ну, Владимир Петрович, а вы что такое?

Жмяков (серьезно). - А я же, Илья Григорьевич, последний мелкий буржуй на свете. Прикажите - и меня не будет.

Девлетов. - Дурите пореже, Жмяков... Но нравитесь вы мне чемто, - черт вас знает...

Жмяков. - А тем, что я счастливый гад, Илья Григорьевич. <...> я человек дешевый и веселый, - я в социализм бубенчиком, бубенчиком вкачусь, позвоню немного и замолкну сам.

3 Источник цитации: «Бедные внебрачные дети современности, сделавшие подлинную революцию в искусстве и - смиренно выжидающие времени... усыновления», был адресован покинувшим лоно «Нового Лефа» Маяковскому, Асееву и Брику. 
Девлетов. - Прямо хуже вредителя, сукин сын! [7, с. 235].

Напускная веселость циника Жмякова рифмуется с названием книги Б. Шкловского «Поиски оптимизма» (I93I) и смыслами эссе «БОД» (I929), принадлежащего перу бывшего конструктивиста К. Зелинского. В эссе утверждается мысль, что для «построения социализма нужны люди полнокровного самочувствия, веселого жизнеощущения», что «каждый шаг мы должны чувствовать радость бытия». Реакция РАПП на новое бодрое мироощущение была жесткой: автор «БОД» рассматривался как спец, «деформированный практикой Октября» и «наполовину духовный эмигрант» [Іо, с. 270-27I]. Как отмечает Н. Умрюхина, статья Л. Авербаха «О целостных масштабах и частных Макарах» отчасти приравняла мысли платоновских героев к рассуждениям Бода. Сам же Платонов, как показало его письмо Ступенкеру, не принял сопоставления себя с Зелинским и резко с ним размежевался: «Самое грустное для меня - сопоставление с Бодом и Сельв-Зелинским. Я этих людей уважаю как литераторов, но не люблю тех, кого они выражают, - советских дельцов-американцев» [Іо, с. 269].

История показала, что Зелинский, подобно Шкловскому, несмотря ни на что, уцелел и сохранил свои позиции в советской литературе, он даже выступил критиком Платонова на вечере ВССП в г932 г. Фраза Девлетова была пророческой в отношении этого «веселого» типажа: «...нравитесь вы мне чем-то - черт вас знает».

Как уже было сказано, в составе главных персонажей пьесы 6 мужчин и одна женщина. И вместе с представительницей «прекрасного пола» в «Высоком напряжении» рождаются и реализуют себя два конфликта политико-социальный, связанный с отношением к невыполнимому встречному промфинплану, и второй, касающийся актуальной для эпохи социалистического строительства темы взаимоотношений полов.

Ольга Крашенина - инженер лет двадцати пяти. Директор завода Девлетов предваряет ее появление на сцене следующей характеристикой: «... она не выходит из цехов по двадцати часов. Вчера я ее нашел спящей в силовой, третьего дня она стояла на ремонте фильтра тридцать часов» [7, с. 2оI]. Зрителю она предстает еле живой от многодневного бдения в комнате Мешкова, к которому она явилась, намереваясь договориться о смене дежурства. Однако в следующей момент она уже спит, побежденная предельной 
усталостью, и... видит во сне компрессорную с испорченным экономайзером. Трудовой энтузиазм этой женщины, граничащий с подвигом, пугает Мешкова, который, склонившись над спящей, говорит: «Они и во сне все чувствуют! Ведь действительно экономайзер в котельной испорчен...! Как я наяву об этом ни разу не вспомнил?!» [7, с. 3І2].

У красавицы Крашениной, подобно другим персонажам пьесы, есть реальный прототип. Его нетрудно было найти по подсказкам в тексте: это первая женщина-инженер турбинщик Металлического завода и специалист по экономайзерам Надежда Дмитриевна Гончарова - потомок писателя И. Гончарова [3, с. 22-24]. Окончившая со вторым выпуском Высшие женские бестужевские политехнические курсы, она проходила практику на питерской электростанции «Гелиос», где всякий раз ей приходилось подписывать бумагу: «В случае моей гибели от несчастного случая в смерти моей прошу никого не винить», так как женщинам инженеры-мужчины не доверяли. После победы в конкурсе на создание лучшей схемы обмотки статора генератора она была приглашена на штатную работу в трамвайной станции Петербурга. Пришлось поработать ей и на приемке угля. В І9I4 г. ее взяли на завод «Экономайзер» как победившую в соревновании двух инженеров на создание формулы расчета теплопередачи ${ }^{4}$. Отметим эту традиционно считающуюся мужской способность ее ума к расчетам и формулам, которую потерял перепуганный Мешков и сохранил, несмотря на все испытания, Абраментов: «Мешков. <...> Ты знаешь, я забыл однажды формулу живой силы! Абраментов - Эм вэ квадрат, деленные на два... [7, с. 204]. По-видимому, память и точность расчетов для Платонова, электротехника и изобретателя, была признаком свободы ума и самообладания, которыми он наделял в набросках к пьесе представителей «нового мира»: «Сюжет: г. Производ. риск. 2) «Нас всех уволят, мы умрем с голоду, мы - старый мир» Я разучился, Я забыл технику, Я забыл формулу энергии» [7, с. І9г].

В г923 г. Гончарова защитила дипломный проект на тему «Электрические станции на подмосковном угле с передачей энергии с места углеразработки» (заметим, что в набросках главная героиня пьесы работала на торфоразработках). И в том же году попыталась поступить на Металличе-

4 Ряд фактов из биографии Н.Д. Гончаровой восстановлен по данным архива ЛМЗ. 
ский завод, в чем ей, как женщине, отказали. Только благодаря поддержке директора завода, «инженера старой школы», А.Ю. Вимблада и возглавлявшего конструкторское бюро по производству водяных турбин В.И. Андреева она все же была принята и работала на ЛМЗ до 8 июля І929 г.

Вряд ли Платонов встречался с ней лично, в то время как Вимблада и Андреева он застал. Однако он не мог не знать о ней - первой, блестящей женщине-турбостроителе. В г929-І93І гг. она работала старшим инженером в турбинной группе объединения «Котлотурбина», оставаясь в той же сфере производственной деятельности, что и первый турбинный цех, где в составе бригады писателей трудился Платонов.

Следует заметить, что Крашенина не просто талантливый инженер. Она прежде всего инициативный организатор производства и человек активной жизненной позиции, коммунистка. Кроме того, она гораздо моложе Гончаровой, которая в 1929 г. была зрелой дамой 43 лет. Напомню, Крашенина - очень красивая 25-летняя девушка.

Образ Крашениной был данью времени - на острие социального заказа. 5 июня І93І г. на заседании МАПП прозвучала критика «Союзкино», указавшая на то, что «выпадет совершенно из тематики <...> участие женщины в социалистическом строительстве»5. Причина тому, как сказал заведующий отделом кадров Союзкино Яковлев, в отсутствии «в промышленности - на Днепрострое, Автострое женщин-активисток. Из фактического материала мы знаем, что там нет, а кино дает только факты без приукрашивания...» ${ }^{6}$.

В фонде Отдела рукописей ИМЛИ РАН сохранились списки членов киносекции Всеросскомдрама, где в І93I-I932 гг. числится «литератор» Платонов, по социальному происхождению «из рабочих» [II, с. 7]. И как член киносекции Платонов, отвечая упрекам Киршона, дает образ женщины-активистки, ударницы, имеющий реальную, фактическую основу.

Активистка Крашенина замужем. Она отчасти аристофанова Лисистрата, о которой говорил Киршон на том же пленуме МАПП 3 июня І93І г., когда громил повесть Платонова «Впрок». Киршон сообщил, что

6 Там же. 
...в ЦЧО встретился с такой историей, когда бабы заявляли, что “мы не будем жить с мужьями”, если они пойдут в колхоз. А комсомолки заявили: “мы будем жить с вашими мужьями”. Причем, поверьте мне, товарищи, что это гораздо более героическая и интересная эпопея, чем Лисистрата. Ибо, надо принять во внимание еще одну деталь, что в этом районе был большой процент зараженных сифилисом, и когда комсомолки говорили, “мы будем жить с мужьями”, многие из них рисковали и могли получить сифилис ${ }^{7}$

Но комсомолка Крашенина «Высокого напряжения» с мужем не живет не из гигиенических соображений, а потому что отдала себя полностью работе. Обнаруживший заснувшую от усталости на постели Мешкова жену Крашенин «в неврозе» кричит: «Оля! Ты забыла меня, девочка? Я ведь твой Коля... Ах ты так, - прочь от меня, сука!! <...> Обезличку, сволочь, на мужьев ввела!» [7, с. 215].

Но, как бы политически актуальна ни была Крашенина, с ней и с Абраментовым связано глубоко трагическое, экзистенциально-высокое звучание любовной темы «Высокого напряжения». Платонов избирает старинный драматургический узел - неразделенную любовь и любовь взаимную, но разделенную смертью, - и работает с фактическим материалом не как хроникер-очеркист, а как поэт. Его документальность, как мы видим на примере Крашениной и Абраментова, не образует сплошной фактности: «Высокое напряжение» - это сплав документальных и воображаемых портретов, что не опровергает достоверности событий. Встреча Крашениной с Абраментовым, возникшее чувство, трагическая разобщенность социальной принадлежностью, примирение на смертном одре и вечная разлука - все это происходит или в цеху на фоне бушующего пламени, или в старинной дворянской усадьбе эпохи русского классицизма, окруженной богатым соловьями садом, принадлежавшей видному царскому сановнику Дурново. Эта усадьба, ставшая клубом им. Сталина ЛМЗ, предоставила свои классические интерьеры для сцены прощания с погибшим Абраментовым и для запоздалого признания в любви. Усадебный державинский хронотоп преодолел не только пространство, но и время: Крашенина и Абраментов, мчавшиеся (или гонимые?), как в античной трагедии, навстречу Року, к 
предрешенному финалу, перешагнули, наконец, порог человеческого земного бытия: Абраментов в гробу на сцене клуба им. Сталина уже принадлежит Вечности, как и любовь к нему Крашениной. Возле гробов суетятся и распоряжаются лишь Жмяковы и Девлетовы, их показное внимание можно уподобить публикациям и инициативам РАПП, посвященным увековечению памяти Маяковского, в частности, присвоению имени Маяковского писательскому клубу: «...ведь Маяковский сам любил идти в рабочие массы» ${ }^{8}$. И вопрос Пужакова над телами жертв борьбы за «встречный» теряет сиюминутный, политически-актуальный смысл: «Вот скоро хорошо уж будет, а тебя нету; - нам, брат, без тебя тоже стыдно оставаться. Ты, значит, сделал, а другие жировать будут, - это ведь неверно!» [7, с. 229].

Член Всеросскомдрама с г93і г., Платонов не мог не быть в курсе дискуссий о Шекспире, развернувшихся в стенах Общества в г93І г. и проникавших в газетную и журнальную публицистику. Так, на заседании МАПП 27 мая г93г г. В. Ермилов обратился к присутствующим с призывом: «Наш лозунг, который мы выбрасываем перед пролетарской литературой: “догнать и перегнать” не какого-нибудь Пильняка, - это не большая честь, да и пролетарская литература уже догнала и перегнала - догнать и перегнать Шекспира...». И объяснил, как это сделать - надо:

...не равняться на их авторитет, учиться у них, но исходить из практики сегодняшнего дня9.

Давать ли конкретно ту или иную личность в разрезе борьбы на производстве или давать его и в разрезе личной жизни, <...> за какое основное звено ухватиться <...>? Первая опасность та, что описывая данную конкретную личность, он не сумеет схватиться за основное звено, за то, что ведет его в борьбе, то, что сделало его передовиком. А вторая опасность - это сусальность, интеллигентское сюсюканье. <..> Чтобы была действительно только такая книжка - как лучше писать? <...> Писатель ставит вопрос таким образом, - нас заставляют давать сегодняшние факты стройки, посылают с бригадами, но как это умещается с задачей борьбы за большое искусство? 
Мысль о том, насколько совместимы «факты стройки» и посылка писательских «бригад» с большим искусством, развивал в своем выступлении во Всеросскомдраме 27 февраля того же г93г г. Афиногенов:

Я познакомился с Шекспиром. Я думал, счастливый, черт возьми, Шекспир, он мог писать о ревности, о скупости, о любви. Ведь все эти чувства из арсенала нашей драматургии изъяты, но можно писать о влиянии промфинплана на психологию рабочих масс, а просто взять какой-нибудь случай - я не могу, потому что я буду назван: перерожденцем, ренегатом и т. п. [II, с. I9I].

И хотя Афиногенов считал поэтику Шекспира несовместимой с ликвидацией прорывов на производстве, а Третьяков высмеивал рапповские потуги «шекспиризации», Платонов смог сказать «о пролетарских Отелло, советских Гамлетах, комсомольских Ромео и интеллигентских професcopax Лир» [І2, с. I], о подлинной ревности, о скупости, о любви, о большой человеческой истории на фоне «крохоборства борьбы» за встречный промфинплан. В «Высоком напряжении», как мы стремились показать, он непротиворечиво сочетал два сюжетно-образных, стилевых, проблемных слоя: документально-биографический и экзистенциальный, позволившие ему поднять повседневность эпохи реконструкции до высот шекспировской трагедии, когда суд над сегодняшним днем вершит вечность. 


\section{Список литературы}

I Андрей Платонов. Воспоминания современников. Материалы к биографии. М.: Сов. писатель, І994. 497 с.

2 Власть и художественная интеллигенция. Документы ЦК РКП(б) - ВКП(б), ВЧК - ОГПУ - НКВД о культурной политике. І9І7-I953. М.: Международный фонд «Демократия», 2002. 87 г с.

3 Исаев В. Одна из пятисот // Техника - молодежи. 1987. № 3. С. 22-24.

4 Корниенко Н.В. Борьба за постановку пьесы «Высокое напряжение». Документы I932 г. // «Страна философов» Андрея Платонова: Проблемы творчества. М.: ИМЛИ РАН, 2ОІг. ВЫп. 7. 652 с.

5 М. Горький и советские писатели. Неизданная переписка. Литературное наследство. М.: Изд-во АН СССР, І963. Т. 70.736 с.

6 Малыгина Н.М. Принципы «производственного» искусства в пьесе А. Платонова «Высокое напряжение» // Вестник московского городского педагогического университета. Серия «Филологическое образование». 2013. № I. С. 62-72. Московская Д.С. Первая редакция пьесы «Высокое напряжение»: «Объявление о смерти» // Архив А.П. Платонова. М.: ИМЛИ РАН, 2009. Кн. І. С. І78-237. Московская Д.С. «Я по существу мастеровой, братцы». Владимир Маяковский в реминисценциях пьесы Андрея Платонова «Высокое напряжение» // Русская литература. 2012. № I. С. I78-193.

9 Платонов А.П. Записные книжки. Материалы к биографии. М.: ИМЛИ РАН, «Наследие», 2000, 42I с.

Iо Платонов А. «...я прожил жизнь»: Письма І920-І950 гг. М.: Астрель, 2013. 688 с.

II Плотников К.И. История литературного объединения Всеросскомдрам: по материалам Отдела рукописей ИМЛИ РАН: дис. ... канд. филол. наук. М., 2015. 258 с.

I2 Третьяков С. Наши товарищи // Новый Леф. І928. № Іо. С. І-2.

I3 Чужак Н. Левее ЛЕФа // Новый Леф. І928. № І2. С. 27-32. 


\section{References}

Andrej Platonov. Vospominanija sovremennikov. Materialy k biografii [Memoirs of contemporaries. Materials for biography]. Moscow, Sovetskij pisatel' Publ., I994. 497 p. (In Russ.) Vlast' $i$ hudozhestvennaja intelligencija. Dokumenty CK RKP(b) - VKP(b), VChK OGPU - NKVD o kul'turnoj politike. I9I7-I953 [Power and artistic intelligentsia. Documents of the Central Committee of the RCP (B) - VKP (b), the Cheka OGPU - the NKVD on cultural policy. I9I7-I953]. Moscow, Mezhdunarodnyj fond “Demokratija” Publ., 2002. 87I p. (In Russ.)

Isaev V. Odna iz pjatisot [One of the five hundred]. Tehnika - molodezhi, I987, no 3, pp. 22-24. (In Russ.)

Kornienko N.V. Bor'ba za postanovku p'esy “Vysokoe naprjazhenie”. Dokumenty I932 g. [The struggle for staging High Voltage. Documents of I932]. "Strana filosofov" Andreja Platonova: Problemy tvorchestva [Andrey Platonov's "country of philosophers": The problems of his work] Moscow, IWL RAN Publ., 20II. Vol. 7. 652 p. (In Russ.) M. Gor'kij i sovetskie pisateli. Neizdannaja perepiska. Literaturnoe nasledstvo [M. Gorky and Soviet writers. Unpublished correspondence. Literary heritage]. Moscow, Izd-vo AN SSSR Publ., I963. Vol. 70. 736 p. (In Russ.) Malygina N.M. Principy “proizvodstvennogo” iskusstva v p'ese A. Platonova "Vysokoe naprjazhenie" [The principle of "manufacture art" in the play High Voltage by Andrey Platonov]. Vestnik moskovskogo gorodskogo pedagogicheskogo universiteta, Serija "Filologicheskoe obrazovanie" [Series "Philological Education”], 20I3, no I, pp. 62-72. (In Russ.) Moskovskaja D.S. Pervaja redakcija p'esy “Vysokoe naprjazhenie”: “Objavlenie o smerti” [The first version of the play High Voltage: The Announcement of Death]. Arhiv A.P. Platonova [A. Platonov's archives]. Moscow, IWL RAS Publ., 2009, vol. I, pp. 178-237. (In Russ.)

Moskovskaja D.S. “Ja po sushhestvu masterovoj, bratcy”. Vladimir Majakovskij v reminiscencijah p'esy Andreja Platonova "Vysokoe naprjazhenie” [“I am essentially a worker, brothers." Vladimir Mayakovsky in the reminiscences of Andrey Platonov's play High Voltage]. Russkaia literature, 2012, no I, pp. I78-I93. (In Russ.) Platonov A.P. Zapisnye knizhki. Materialy k biografii [Notebooks. Materials for biography]. Moscow, IWL RAS, "Nasledie” Publ., 2000, 42I p. (In Russ.) Platonov A. “...ja prozhil zhizn": Pis"ma I920-I950 gg. [“... I lived my life”: Letters I920-I950]. Moscow, Astrel’ Publ., 2013, 688 p. (In Russ.) Plotnikov K.I. Istorija literaturnogo ob'edinenija Vserosskomdram: po materialam Otdela rukopisej [The history of the literary association Vserosskomdram: based on the materials of the Department of Manuscripts of the IWL RAS] IWL RAS. Dissertacija... kandidata filologicheskih nauk [PhD Thesis in Philology]. Moscow, 20I5. 258 p. (In Russ.) 
Русская литература / Д.С. Московская

I2 Tret’jakov S. Nashi tovarishhi [Our comrades]. Novyj Lef, I928, no ı,, pp. I-2. (In Russ.)

I3 Chuzhak N. Levee LEFa [More Left than LEF]. Novyj Lef, I928, no ı2, pp. 27-32. (In Russ.) 